\title{
Tip 2 diabetes mellitus hastalarında hipergliseminin kardiyak repolarizasyon
} parametrelerine akut etkileri

\author{
Acute effects of hyperglisemia on cardiac repolarisation parameters in patients with \\ type 2 diabetes mellitus \\ Evrim ŞIMŞEK(D)
}

Ege Üniversitesi Tıp Fakültesi Kardiyoloji Anabilim Dalı, İzmir, Türkiye

Öz

Amaç: Ani kardiyak ölüm tip 2 Diabetes Mellitus (DM) hastalarında daha sık görülmektedir. Aritmi riskinin belirlenmesi için elektrokardiografide (EKG) repolarizasyonu gösteren QT intervali ve T dalgasının tepesinden sonuna kadar olan süreyi tanımlayan "T wave peak to end time" (Tpe) intervali yararlı olabilmektedir. Bu parametrelerin tip 2 DM hastalarında genel popülasyona göre değişimi fazla çalışılmamıştır. Hastaların hipergilisemik ve normoglisemik dönemlerinde bu parametreleri içeren karşılaştırma ise daha önce yapılmamıştır.

Çalışmanın amacı tip 2 DM hastalarında aritmik riskin göstergesi olabilecek QT ve Tpe parametrelerin sağlıklı kontrol grubuyla karşılaştırılması ve hastaların hiperglisemik ve normoglisemik dönemlerinde bu parametrelerdeki değişimin gösterilmesidir.

Gereç ve Yöntem: İnsülin infüzyonu başlanan 30 tip 2 DM hastası ile benzer yaş ve cinsiyette 30 sağlıklı birey çalışmaya alınmıştır. DM hastaların insülin infüzyonu öncesi ve sonrası EKG'leri çekilmiş, QT, Tpe ve kalp hızları ölçülüp kalp hızına göre düzeltilmiş QT (QTc), sırasıyla kalp hızı ve QTc ye göre düzeltilmiş, Tpec ve TpeQTc değerleri hesaplanıp hem kendi aralarında hem de sağlıklı kontrol grubunun ölçümleri ile karşılaştırılmıştır.

Bulgular: Hastaların ortalama yaşı 54,2 yıl ve \%53,3'ü kadındı. Hasta grubunda hiperglisemik ve normoglisemik dönemde kontrol grubuna göre kalp hızı daha yüksek, Tpec ve QTc süreleri istatistiksel olarak daha uzundu. Hiperglisemik dönem ile normoglisemik dönem kendi aralarında karşılaştırldığında QTc, Tpe, Tpec, TpeQTc parametrelerinin hepsi hiperglisemik dönemde daha uzun bulundu. (Sırasıyla QTc:453 \pm 31 'e karşı 434 $\pm 33 p=0,003$, Tpe:95,2 $\pm 11,9$ 'a karşı 82,3 $\pm 11,8 p<0,001$, Tpec:112,5 $\pm 18,1$ 'e karşı 96,4 $\pm 16,1 p<0,001$, TpeQTc:0,210 $\pm 0,023$ 'e karşı 0,190 $\pm 0,02 p<0,001$ )

Sonuç: Tip 2 DM hastalarında QTc, Tpec parametreleri sağlıklı kişilere göre uzunken hiperglisemik dönemde bu parametreler normoglisemik döneme göre daha da uzundur. Bu nedenle DM hastaların aritmik riskleri hiperglisemik dönemde daha da yüksek olabilir.

Anahtar Sözcükler: Tip 2 diabetes mellitus, ventriküler repolarizasyon, aritmiler, elektrokardiyografi.

\begin{abstract} normoglycemic periods has not been evaluated before.

\footnotetext{
Yazışma Adresi: Evrim Şimşek

Ege Üniversitesi Tıp Fakültesi Kardiyoloji Anabilim Dalı, İzmir,

Türkiye

E-mail: drevrimsimsek@gmail.com

Makalenin Geliş Tarihi: 15.10.2019 Kabul Tarihi: 11.11.2019
}

Aim: Sudden cardiac death is more common in patients with type 2 diabetes mellitus (DM). Repolarization parameters on electrocardiography (ECG) including the QT and Tpe interval may be useful for determining the arrhythmic risk. Comparison of these parameters in patients with type 2 DM and healthy individuals has not been studied much. Also, the difference between hyper and 
The aim of this study was to compare the QT and Tpe in type 2 DM patients with control group and to show the differences in the hyper and normoglycemic periods.

Materials and Methods: Thirty type 2 DM patients needed insulin infusion and 30 healthy individuals of similar age and sex were included in the study. ECGs performed before and after insulin infusion. $Q T$, Tpe and heart rates were measured, and $Q T$ corrected for heart rate (QTC), Tpe corrected for heart rate (Tpec) and QTc (TpeQTc) values were calculated. Results of the hyper and normoglycemic status and control group were compared.

Results: The mean age of the patients was 54.2 years and $53.3 \%$ of them were female. Heart rate was higher and Tpec and QTc periods were statistically longer in the both hyper and normoglycemic period compared to the control group. QTc, Tpe, Tpec, TpeQTc parameters were longer in hyperglycemic period than normoglycemic period (QTc:453 \pm 31 to $434 \pm 33 p=0.003$, Tpe:95.2 \pm 11.9 to $82.3 \pm 11.8 p<0.001$, Tpec:112.5 \pm 18.1 to $96.4 \pm 16.1 p<0.001$, TpeQTc:0.210 \pm 0.023 to $0.190 \pm 0.02$ $p<0.001$ ).

Conclusion: QTC and Tpec parameters were longer in patients with type 2 DM than in healthy subjects, whereas these parameters were longer in hyperglycemic period than in normoglycemic period. Therefore, arrhythmic risks of DM patients may be even higher in the hyperglycemic period.

Keywords: Type 2 diabetes mellitus, arrhythmias, ventricular repolarization, electrocardiography.

\section{Giriş}

Diabetes Mellitus (DM) kötü kardiyovasküler sonlanma ile ilişkili bir hastalıktır. Hem tip 1 hem de tip 2 DM hastalarında artmış koroner arter hastalığı, kalp yetmezliği prevalansı bildirilmiştir $(1,2)$. Ayrica bu hasta grubunda ani kardiyak ölüm oranları da yüksektir $(3,4)$. Koroner arter hastalığı en önemli makrovasküler komplikasyon olarak dikkati çekse de ani kardiyak ölümün gelişmesinde olasılıkla diyabetik mikrovasküler komplikasyon olan kardiyak otonom nöropati (KON) ve miyokardiyal iyon kanalı patolojilerinin neden olduğu aritmiler rol oynamaktadır $(3,5)$.

Hastaların aritmik risklerini yüzey elektrokardiyografi (EKG) ile tahmin edebilecek parametreler, genel popülasyonda ve özellikle kalp yetmezliği hastalarında tanımlanmaya çalışılmıştır. Özellikle ölümcül ventriküler aritmilerin gelişimi açısından en hassas olan repolarizasyon dönemi patolojilerini gösteren QT intervali, kalp hızına göre düzeltilmiş QT intervali (QTc), QT intervali dispersiyonu ve son zamanlarda QT den daha etkili bir belirteç olduğu gösterilmiş olan $T$ dalgası tepe ve sonu ( $T$ wave peak to end time: Tpe) süreleri yol gösterici olmaktadır (6-8). Ani kardiyak arrest öyküsü olan hastalarda QTc ve Tpe uzaması, sağlıklı kontrol grubuna göre sırasıyla 4,9 ve 2,1 kat fazla bulunmuştur (7). Tip 1 ve $2 \mathrm{DM}$ hastalarında da makrovasküler komplikasyonlardan önce gelişen EKG değişiklikleri belirtilmiştir. DM hastalarında QT ve QTc intervallerinde uzama, birçok çalışmada gösterilmiş olsa da sadece bazılarında istatistiksel anlamlıığa ulaşmıştır (9-12). QTc süresindeki uzamanın özellikle otonom nöropati gelişmiş hastalarda daha fazla olduğu gösterilmiştir (13). Repolarizasyon patolojilerini ve özellikle transmural repolarizasyon dispersiyonunu dolayısıyla da aritmik riski QTc'ye göre daha hassas gösteren Tpe ölçümü ise DM hastalarında çok çalışılmamıştır (14). KON kronik süreçte gelişen bir durum olsa da DM'ye bağlı aritmilerin erken dönemde özellikle hiperglisemiye bağlı iyon kanalı patolojilerinden kaynaklanabileceği düşünülmektedir (3). Ancak akut kan şekeri değişikliklerinin miyokardiyal elektriksel aktiviteye etkileri ve bu durumun EKG'ye yansıması ise en az çalışılan konudur. Mevcut DM çalışmalarının birçoğu EKG çekilmesi sırasındaki kan glikoz düzeylerini değerlendirmeye almamıştır. Hayvan deneyleriyle DM oluşturulan farelerde hiperglisemiye bağlı olası aritmi gelişim mekanizmaları araştırılmıştır (5).

Çalışmanın amacı diyabet tanısı olan ve kan şekeri regülasyonu sağlanamayıp insülin infüzyonu başlanan hastalarda, hiperglisemik ve insülin infüzyonu kesildikten hemen sonra normoglisemik dönemde çekilen EKG'lerde aritmi riskinin önemli göstergeleri olan QT, QTc ve Tpe, Tpec gibi repolarizasyon parametrelerindeki değişikleri saptamaktır.

\section{Gereç ve Yöntem}

Ocak 2019 - Temmuz 2019 tarihleri arasında çalışma merkezinde endokrinolog tarafından DM tanısıyla insülin infüzyonu başlanması kararı verilen hastalar değerlendirmeye alınmıştır. Yaş aralığı 18-75 olan, bilgilendirilmiş gönüllü olur 
formunu imzalayan, QT mesafesini uzatacak ilaç kullanımı olmayan ve sinüs ritmindeki 30 hasta çalışmaya dahil edilmiştir. Hastaların hiperglisemik dönemde insülin infüzyonu başlanmadan önce EKG'leri çekilmiş ardından kan glikoz düzeyleri kontrol altına alındıktan ve insülin infüzyonu kesildikten hemen sonra kontrol EKG'leri çekilmiştir. EKG'ler dijital EKG cihazı ile çekilerek elektronik hasta dosyasında saklanmışlardır. Hastaların tıbbi öyküsü ve rutin laboratuvar tetkikleri ve kullandığı ilaçlar olgu rapor formuna kaydedilmiştir.

Bilgilendirilmiş gönüllü olur formunu imzalayan, bilinen kardiyovasküler hastalık öyküsü olmayan, hasta grubuyla benzer yaş ve cinsiyette 30 gönüllünün de EKG'leri çekilerek kontrol grubu oluşturulmuştur. Çalışma için etik kurul onayı alınmıştır (Karar no:18-6/43).

\section{Elektrokardiyografi}

On iki derivasyonlu EKG $10 \mathrm{~mm} / \mathrm{mV}$ amplitüdünde ve $25 \mathrm{~mm} / \mathrm{sn}$ kâğıt hızında istirahat sonrası supin pozisyonda dijital EKG cihazı (CardiMax FX-8222, Fukuda Denshi, Tokyo, Japonya) ile insülin infüzyonu öncesi ve sonrasında çekilmiştir.

Hastaların EKG'leri hastaların klinik durumlarından ve EKG çekim zamanlarından habersiz tek bir kardiyolog tarafından özel yazılım kullanarak (EP Calipers for MacOs v1.19.1, EP Studios, ABD) gerekli ölçümler (kalp hızı, QT intervali ve Tpe süreleri) yapılmıştır.

QT intervali QRS başlangıcından T dalgasının izoelektrik çizgiye indiği noktaların arası olarak kabul edildi. QT süresinin kalp hızına göre düzeltilmesinde (QTc) Bazett formülü kullanıldı (QTC $=\mathrm{QT} / \sqrt{R} R$ ).

Tpe süresi daha önce literatürde tanımlanan yöntemler kullanılarak ölçüldü. Ölçüm için öncelikle V5 derivasyonu kullanıldı. Bu derivasyonun uygun olmaması durumunda (yoğun artefakt ya da T dalga amplitüdü $\leq 1,5 \mathrm{mV}$ ) sırasıyla V4 ve V6 derivasyonları kullanıldı. Tpe süresi $T$ dalgasının en yüksek olduğu noktadan izoelektrik hatta indiği nokta arası olarak ölçüldü. $T$ dalgasının sonunda düşük amplitüdlü sinyaller mevcut ve izoelektrik hatta inişi net değerlendirilemiyor ise $T$ dalgasının inen koluna teğet bir doğru çizilip bu doğrunun izoelektrik hattı kestiği nokta $\mathrm{T}$ dalgasının sonu olarak kullanıldı. Tpe süresinin literatürde tanımlanan QTc ve kalp hızına göre düzeltilmesi için TpeQtc: Tpe/QTc ve Tpec: Tpe $/ \sqrt{R} R$ formülleri kullanıldı.

\section{İstatistik}

Değişkenlerin normal dağılımı KolmogorovSmirnov testi ile belirlendi. Normal dağılan devamlı değişkenler ortalama ve standart sapma (sd: standart deviation), normal dağılmayan devamlı değişkenler ise ortanca ve minimummaksimum olarak belirtilirken kategorik değişkenler yüzde ve olgu sayısı olarak belirtildi. İnsülin infüzyonu öncesi hiperglisemik dönem ile normoglisemik dönem ölçümlerinden devamlı değişkenler tekrarlayan ölçümlerin değerlendirmesinde kullanılan eşlenmiş $\mathrm{t}$ testi, kategorik değişkenler ise McNemar testi ile karşılaştırıldı. Kontrol grubu ile DM hasta grubu arasındaki karşılaştırmalarda devamlı değişkenler için normal dağılım paternine göre $t$ test ya da Mann-Whitney $U$ testi kullanılırken, kategorik değişkenler için ki kare ya da Fisher'in Exact testi kullanılmıştır.

Rastgele seçilen 10 hastanın EKG'si aynı gözlemci tarafından tekrar değerlendirilirken sonuçlardan habersiz tecrübeli başka bir kardiyolog tarafından da değerlendirdi. $\mathrm{Bu}$ sonuçları kullanarak Tpe ve QT ölçümü için gözlemci içi ve gözlemciler arası değişkenlik hesaplandı. $P$ değeri $<0,05$ olması istatistiksel olarak anlamlı kabul edildi. Tüm karşılaştırmalar SPSS (Statistical Package for Social Sciences) v20 (IBM, Armonk, NY, ABD) istatistik paket programı kullanılarak yapılmıştır.

\section{Bulgular}

Çalışmaya dahil edilme kriterlerine uyan 30 hasta ve sonrasında benzer yaş ve cinsiyette sağlıklı 30 gönüllü çalışmaya alınmıştır. Hasta grubunun ortalama yaşı $54,2 \pm 12,2$ ve \%53,3'ü kadındı. Çalışmaya alınan hastaların tamamı tip 2 DM hastası idi. Hastaların \%60'ında hipertansiyon, $\% 13,3$ 'ünde kronik böbrek yetmezliği ve \%13,3'ünde koroner arter hastalığı vardı. Hiçbir hastada tanı koyulmuş klinik kalp yetmezliği yoktu ve ortalama sol ventrikül ejeksiyon

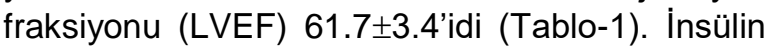
infüzyonu başlandığında hastaların tamamının kan glikoz düzeyi $310 \mathrm{mg} / \mathrm{dl}$ üstünde olup ortalama $394 \pm 81 \mathrm{mg} / \mathrm{dl}$ idi. Hastalar 3 gün süre ile insülin infüzyonu almıştır. Hastaların ortalama $\mathrm{HbA} 1 \mathrm{c}$ değerleri \%10,6 $\pm 3,3$ iken, ilk tanı anından çalışmaya alınan süreyi içeren DM süresi $10,2 \pm 7,4$ yıldı. Sağlıklı kontrol grubuyla karşılaştırıldığında hasta grubuyla yaş ve cinsiyet açısından fark bulunmazken beklendiği gibi DM grubunda vücut kitle indeksi ve $\mathrm{HbA} 1 \mathrm{c}$ düzeyleri

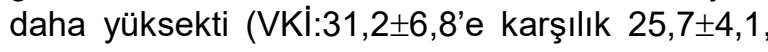

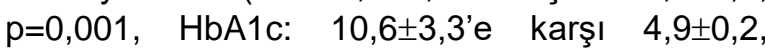


$p<0,001)$. Hasta grubunda klinik kalp yetmezliği bulunmamasına rağmen LVEF kontrol grubuna göre daha düşüktü (Sırasıyla \%61,7 $\pm 3,4$ 'ekarşı $64,9 \pm 3,1, p<0,001$ ) (Tablo-1).

EKG parametrelerine bakıldığında hiperglisemik dönemdeki ortalama kalp hızı $84 \pm 13$ vuru/dk, QTc 453 $\pm 31 \mathrm{~ms}$ ve Tpe 95,2 $\pm 11,9^{\prime}$ idi. Patolojik değer olarak tanımlanan QTc için erkeklerde 450 ms kadınlarda $460 \mathrm{~ms}$ değerlerini geçen kişi oranı \%43 iken Tpe için $89 \mathrm{~ms}$, Tpec için $90 \mathrm{~ms}$ patolojik değerindeki hasta oranları sırasıyla $\% 73,3$ ve $\% 93,3$ 'tür $(7,15)$.

Kontrol grubu ile karşılaştırıldığında hiperglisemik dönemdeki hasta grubunda kalp hızı daha yüksekti. Kalp hızına göre düzeltilmemiş olarak değerlendirildiğinde QT süresi hasta grubunda daha kısa olsa da kalp hızına göre düzeltilmiş QTc değerleri hasta grubunda daha uzundu (QTc

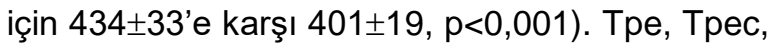
TpeQTc değerleri de istatistiksel anlamlı olarak hasta grubunda daha uzundu (Tablo-2). Kontrol grubunda patolojik QTc ve Tpe değerlerini geçen kişi bulunmazken patolojik Tpec değerini geçen dört kişi $(\% 13,3)$ bulunmaktaydı. Bu oranların hepsi anlamlı olarak hasta grubunda daha yüksekti (QTc için \%43'e karşı \%0 p<0,001, Tpe için \%73,3'e karşı \%0 p<0,001, Tpec için \%93,3'e karşı \%13,3 $p<0,001)$. Kısaca bütün repolarizasyon parametreleri DM hasta grubunda kontrol grubuna göre ortalama olarak da patolojik sınırları geçen kişi sıklığı olarak da daha kötüydü.
Insülin infüzyonu kesilip tokluk kan glikoz düzeyi kabul edilebilir değerlere indikten sonra (EKG çekilmeden önce ölçülen kan glikoz seviyesi tüm hastalarda $200 \mathrm{mg} / \mathrm{dl}$ altında olup ortalama $155,5 \pm 26,4 \mathrm{mg} / \mathrm{dl}$ 'dir). Çekilen EKG parametreleri ile hiperglisemik dönem EKG'leri karşılaştırıldığında kalp hızında anlamlı bir değişiklik olmazken (84 \pm 13 'e karşı $82 \pm 14$ $p=0,369)$ çalışma sırasında değerlendirilen bütün repolarizasyon parametrelerinin (QT, QTc ve Tpe, Tpec, TpeQTc) istatistiksel olarak anlamlı bir şekilde kısaldığı izlendi. Bu duruma paralel olarak patolojik sınır QTc, Tpe ve Tpec değerlerini geçen hasta oranları da azalmıştır (Tablo-3).

Normoglisemik dönem EKG'leri kontrol grubu ile karşılaştırıldığında hastalardaki $\mathrm{KH}$ dışındaki bütün parametrelerin azaldığı izlense de hiçbir parametre kontrol grubundan daha iyi değerlere ulaşamamıştır. DM hasta grubunda QTc ve Tpec değerleri, tedavi sonrası dahi kontrol grubuna göre istatistiksel anlamlı olarak daha uzundur (QTc için $434 \pm 33 m s$ 'ye karşı $401 \pm 19 p<0,001$, Tpec 96,4 $\pm 16,1$ 'e karşı $81,9 \pm 7,8 \quad p<0,001$ ) (Tablo-4).

Tpe için gözlemci içi korelasyon katsayısı 0,905, gözlemciler arası korelasyon katsayısı ise 0,808 bulunurken QT için gözlemci içi korelasyon katsayısı 0,915, gözlemciler arası korelasyon kat sayısı ise 0,855 bulunmuştur. Bu sonuçlar her iki parametre için de çok iyi gözlemci içi ve gözlemciler arası uyum olduğunu göstermiştir.

Tablo-1. Hasta ve kontrol gruplarının bazal özellikleri.

\begin{tabular}{|c|c|c|c|}
\hline & Hasta grubu $(n=30)$ & Kontrol grubu $(n=30)$ & $p$ \\
\hline Yaş (yıl) $\pm s d$ & $54,2 \pm 12,2$ & $54,1 \pm 4,1$ & 0,979 \\
\hline Kadın Cinsiyet \% (n) & $53,3(16)$ & $53,3(16)$ & 1 \\
\hline VKI $\left(\mathrm{kg} / \mathrm{m}^{2}\right) \pm \mathrm{sd}$ & $31,2 \pm 6,8$ & $25,7 \pm 4,1$ & 0,001 \\
\hline LVEF (\%) \pm sd & $61,7 \pm 3,4$ & $64,9 \pm 3,1$ & $<0,001$ \\
\hline Sistolik KB $(\mathrm{mmHg}) \pm \mathrm{sd}$ & $130,6 \pm 9,9$ & $127 \pm 8,6$ & 0,132 \\
\hline Diyastolik KB (mmHg) $\pm s d$ & $83,5 \pm 7,5$ & $71,7 \pm 10,3$ & $<0,001$ \\
\hline Total kolesterol $(\mathrm{mg} / \mathrm{dl}) \pm \mathrm{sd}$ & $177,5 \pm 4,2$ & $163,5 \pm 12$ & 0,090 \\
\hline $\mathrm{LDL}(\mathrm{mg} / \mathrm{dl}) \pm \mathrm{sd}$ & $97,38 \pm 30,1$ & $96,57 \pm 13,1$ & 0,894 \\
\hline $\mathrm{HDL}(\mathrm{mg} / \mathrm{dl}) \pm \mathrm{sd}$ & $42,3 \pm 23,7$ & $44,93 \pm 4,9$ & 0,518 \\
\hline $\mathrm{TG}(\mathrm{mg} / \mathrm{dl}) \pm \mathrm{sd}$ & $220,7 \pm 84,4$ & $176,07 \pm 22,4$ & $<0,001$ \\
\hline HT \% (n) & $60(18)$ & 0 & \\
\hline KBY \% (n) & $13,3(4)$ & 0 & \\
\hline $\mathrm{KAH} \%(\mathrm{n})$ & $13,3(4)$ & 0 & \\
\hline $\mathrm{HbA1c}(\%)$ & $10,6 \pm 3,3$ & $4,9 \pm 0,2$ & $<0,001$ \\
\hline Diyabet Süre (yıl) & $10,2 \pm 7,4$ & - & - \\
\hline Sigara \% (n) & 26,7 (8) & $63,3(19)$ & 0,004 \\
\hline
\end{tabular}

(HDL: Yüksek dansiteli kolesterol, HT: Hipertansiyon, KAH: Koroner arter hastalığı, KB: Kan Basıncı, KBY: Kronik böbrek yetmezliği, LDL: Düşük dansiteli kolesterol, LVEF: Sol ventrikül ejeksiyon fraksiyonu, TG: Trigliserid, VKi: Vücut kitle indeksi). 
Tablo-2. Diyabetik hasta grubunun tedavi öncesi değerleri ile kontrol grubunun karşılaştırılması.

\begin{tabular}{llll}
\hline & Tedavi öncesi & Kontrol & p \\
\hline Kalp hızı (vuru/dk) & $84 \pm 13$ & $64 \pm 5$ & $<0,001$ \\
QT $(m s) \pm$ sd & $386 \pm 33$ & $389 \pm 9$ & 0,577 \\
QTc $(m s) \pm$ sd & $453 \pm 31$ & $401 \pm 19$ & $<0,001$ \\
Tpe $(m s)$ & $95,2 \pm 11,9$ & $79,4 \pm 6,3$ & $<0,001$ \\
TpeQTc & $0,210 \pm 0,023$ & $0,198 \pm 0,015$ & 0,018 \\
Tpec $(m s)$ & $112,5 \pm 18,1$ & $81,9 \pm 7,8$ & $<0,001$ \\
Uzun QTc \% (n) & $43,3(13)$ & 0 & $<0,001$ \\
Tpe>89 ms \% (n) & $73,3(22)$ & 0 & $<0,001$ \\
Tpec>90 ms \% (n) & $93,3(28)$ & $13,3(4)$ & $<0,001$ \\
\hline
\end{tabular}

Tablo-3. Diyabetik hasta grubunun tedavi öncesi ve sonrası değerlerinin karşılaştırılması.

\begin{tabular}{llll}
\hline & Tedavi Öncesi & Tedavi Sonrası & $\mathbf{p}$ \\
\hline Kalp hızı (vuru/dk) & $84 \pm 13$ & $82 \pm 14$ & 0,369 \\
QT (ms) \pm sd & $386 \pm 33$ & $374 \pm 30$ & 0,017 \\
QTc (ms) \pm sd & $453 \pm 31$ & $434 \pm 33$ & 0,003 \\
Tpe (ms) & $95,2 \pm 11,9$ & $82,3 \pm 11,8$ & $<0,001$ \\
TpeQTc & $0,210 \pm 0,023$ & $0,190 \pm 0,02$ & $<0,001$ \\
Tpec (ms) & $112,5 \pm 18,1$ & $96,4 \pm 16,1$ & $<0,001$ \\
Uzun QTc \% (n) & $43,3(13)$ & $23,3(7)$ & 0,07 \\
Tpe>89 ms \% (n) & $73,3(22)$ & $26,7(8)$ & $<0,001$ \\
Tpec>90 ms \% (n) & $93,3(28)$ & $63,3(19)$ & 0,012 \\
\hline
\end{tabular}

Tablo-4. Diyabetik hasta grubunun tedavi sonrası değerleri ile kontrol grubunun karşılaştırılması.

\begin{tabular}{llll}
\hline & Tedavi Sonrası & Kontrol & $\mathbf{p}$ \\
Kalp hızı (vuru/dk) & $82 \pm 14$ & $64 \pm 5$ & $<0,001$ \\
QT (ms) \pm sd & $374 \pm 30$ & $389 \pm 9$ & 0,011 \\
QTc (ms) \pm sd & $434 \pm 33$ & $401 \pm 19$ & $<0,001$ \\
Tpe (ms) & $82,3 \pm 11,8$ & $79,4 \pm 6,3$ & 0,241 \\
TpeQTc & $0,190 \pm 0,02$ & $0,198 \pm 0,015$ & 0,093 \\
Tpec (ms) & $96,4 \pm 16,1$ & $81,9 \pm 7,8$ & $<0,001$ \\
Uzun QTc \% (n) & $23,3(7)$ & 0 & $<0,001$ \\
Tpe>89 ms \% (n) & $26,7(8)$ & 0 & $<0,001$ \\
Tpec $>90$ ms \% (n) & $63,3(19)$ & $13,3(4)$ & $<0,001$ \\
\hline
\end{tabular}

\section{Tartışma}

Mevcut çalışma DM hastalarında hiperglisemik dönemde EKG'de ölümcül ventriküler aritmiler için en hassas olan dönem olarak tanımlaman repolarizasyon dönemini gösteren QTc, Tpe, Tpec sürelerinin sağlıklı kontrol grubuna göre anlamlı olarak daha uzun olduğunu ve kan glikoz düzeyi regülasyonun hemen sonrasında patolojik olan parametrelerdeki sürelerin kısaldığını ancak Tpec ve QTc sürelerinin kontrol grubuna göre uzunluğunun devam ettiğini göstermektedir.

DM hastalarında kötü kardiyovasküler sonlanımda koroner arter hastalığı gibi makrovasküler komplikasyonların yanında 
mikrovasküler komplikasyonların da rol oynadığı bilinmektedir $(1,16)$. KON diyabetik hastalarda en çok çalışılmış mikrovasküler komplikasyondur. KON'da özellikle parasempatik lifler etkilenirken sempatik innervasyon korunmaktadır. Bu nedenle hastalarda artmış sempatik sistem aktivasyonu mevcuttur (17, 18). EKG'de artmış sempatik aktivasyonun en belirgin bulgusu kalp hızında artıştır (10, 11). Çalışmamızda da hasta grubunda kalp hızı kontrol grubuna göre yüksek

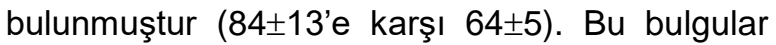
Adebayo ve ark. Tip 2 DM hastalarında 24 saat Holter kayıtlarında ortalama kalp hızlarının sağlıklı kontrol grubuna göre artmış olduğunu gösterdikleri çalışma ile de uyumludur (19). Palova ve ark. ise hastaları KON varlığına göre gruplandırdıktan sonra bu grupları kendi aralarında ve sağlıklı kontrol grubu ile karşılaştırmışlardır. KON olanlarda olmayanlara göre kalp hızı daha yüksek çıksa da her iki grupta da kalp hızı sağlık kontrol grubuna göre yüksektir (11). Bu nedenle DM hastalarda kalp hızı yüksekliğinin en önemli nedeni KON gibi görünse de KON olmadan da kalp hızı yüksektir. Ancak diğer çalışmalar ölçüm sırasında kan glikoz düzeylerinden bahsetmezken mevcut çalışma ayıca hiperglisemik dönemle normoglisemik dönem arasında kalp hızında fark olmadığını

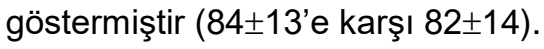

QT intervali kardiyak depolarizasyon ve repolarizasyon süresini gösteren basit ve girişimsel olmayan bir testtir. QT intervalinde en uzun sürede gelişen olay repolarizasyon sürecidir ve bu dönem miyokardın aritmi açsından en hassas olduğu dönemdir. QT intervalinin kalp yetmezliği, koroner arter hastalığı gibi birçok durumda uzadığı ve artmış aritmi ve kardiyovasküler ölümlerle ilişkili olduğu birçok çalışma ile gösterilmiştir (20-22). Tpe intervali ise transmural repolarizasyondaki dağılımı göstermektedir (14). Bu sürede epikard tamamen repolarize olup gelen uyarılara açık halde iken subendokardiyal $\mathrm{M}$ hücreleri repolarizasyonuna devam etmektedir. Transmural repolarizasyonun heterojen hale gelmesi repolarizasyon dispersiyonunu ve EKG'deki yansıması olarak Tpe süresini uzatmaktadır. Bu durum erken geç depolarizasyon (Early after depolarisation) ve polimorfik ventriküler taşikardiye yatkınlığı arttırmaktadır (23-25). Hipertrofik kardiyomiyopati hastalarında Tpe intervalinin ani kardiyak ölümü öngörme gücünün QTc'den daha yüksek olduğu gösterilmiştir (26). Aro ve ark. hastane dışı ani kardiyak ölüm gelişen hastalarında yaptıkları çalışmada QTc ve Tpe uzaması ile AKÖ ilişkisini göstermişlerdir (7).

DM hastalarında aritmik olayları öngörme açısından QTc intervali başka çalışmalarda ele alınmıştır. Zdarska ve ark. 22 tip 1 DM hastasında benzer sayıdaki kontrol grubuna göre QTc intervalinde istatistiksel anlamlı bir fark saptamamış benzer şekilde Palova ve ark. diyabetik hastaları KON açısından gruplandırdıktan sonra QTc sürelerini karşılaştırdıklarında istatistiksel anlamlı farklılık olmadığını göstermişlerdir $(10,11)$. Bu çalışmalardan farklı olarak ise Kuzu ve ark. tip 2 DM hastalarında kontrol grubuna göre QTc intervallerinin daha uzun olduğunu göstermiştir (12). Mevcut çalışmada ise hasta grubunda hiperglisemik dönemde daha belirgin olmakla birlikte kontrol grubuna göre QTc'de istatistiksel anlamlı uzama gösterilmiştir. Bu sonuçta ayrıca dikkat edilmesi gereken durum, hiperglisemik dönemden normoglisemik döneme geçişte QTc süreleri arasında istatistiksel anlamlı düşüş olmasıdır. $\mathrm{Bu}$ durum hipergliseminin akut etkilerini göstermesinin yanında DM hastalarında QTc değerlendirme çalışmalarında çıkan sonuçların uyumsuz olmasının nedeninin hastaların kan glikoz düzeylerindeki farklılığa bağlı olabileceğini düşündürmekledir. Marfella ve ark. 20 sağlıklı kişide akut glikoz yüklemesini takiben $120 \mathrm{dk}$. içinde çekilen EKG'lerinde QTc intervallerinde anlamlı uzamayı gösterdikleri çalışmaları da sonuçlarımızı desteklemektedir (27).

Tpe intervali ise DM hastalarnda QTc'ye göre çok daha az çalışmada değerlendirilmiş bir parametredir ve bazı hastalıklarda aritmik olaylarla ilişkisinin QTc'den daha iyi olduğu gösterilmiştir (26). Diyabetik hastaların Tpe açısından değerlendirildiği iki çalışmada da Tpe, TpeQTc parametreleri kontrol grubuna göre istatistiksel anlamlı olarak daha uzun saptanmıştır $(12,28)$. Çalışmalarda hastaların kan glikoz düzeylerindeki değişim ile EKG parametrelerindeki ilişki değerlendirilemese de Tokatlı ve ark. yaptıkları çalışmada kan glikoz düzeyi ile Tpe süresi arasında anlamlı ancak zayıf korelasyon gösterilmiştir $(p<0,001 \quad r=0,35)$ (28). Mevcut çalışmada ise Tpe, TpeQTc ve Tpec değerleri hiperglisemik dönemde diğer çalışmalardaki gibi kontrol grubuna göre daha uzun bulunurken kan glikoz düzeyi kontrolü sonrası anlamlı olarak kısalmıştır. Glikoz düzeyi kontrolü sonrası Tpe değeri kontrol grubu ile benzer olarak izlense de kalp hızına göre 
düzeltilmiş Tpec değeri kontrol grubundan uzun olmaya devam etmiştir (Tablo-2 ve Tablo-3).

Mevcut çalışmanın hem QTc hem de Tpe ile ilgili sonuçları diyabetik hastalarda miyokardiyal repolarizasyonun bozulduğu hipotezini literatürdeki diğer çalışmalarla uyumlu şekilde desteklemektedir. Ancak mevcut çalışma hastalardaki glikoz düzeyinin akut kontrolü sonrası bozulan miyokardiyal repolarizasyon parametrelerinde düzelme olabileceğini göstermesi açısından özgündür.

Diyabetik hastalardaki repolarizasyon patolojileri ve aritmiler genel olarak KON'a bağlı artmış sempatik aktivite ile açıklanmaya çalışıısa da mevcut çalışmadaki gibi akut glikoz düzeyi değişimlerinin de repolarizasyon bozukluklarına yol açması sadece hipergliseminin nöropatiden bağımsız olarak miyokardial hücrelerdeki aksiyon potansiyeline etkisi olabileceği düşündürmektedir $(5,29)$. Insanlarda hücresel düzeyde hipergliseminin etkilerini araştıran çalışma olmasa da hayvan çalışmalarında diyabetik deneklerde hipergliseminin iyon kanallarına olan etkisi gösterilmiştir. Farelerde voltaj gated potasyum kanal ekspresyonun, yavaş düzenleyici potasyum kanallarında akımın azaldığı gösterilmiştir. Ayrıca artmış oksidatif stresi ve azalmış NO salınımına bağlı olarak $\mathrm{Na}^{+} \mathrm{K}^{+}$ATPaz aktivitesinde azalma ve sitozolik $\mathrm{Ca}^{++}$artışının olduğu gösterilmiştir (3, $5,27)$. Diyabetik hastalarda akut hipergliseminin hücresel etkileri gösterilemese de Koivikko ve ark. çalışmasında 11 tip $1 \mathrm{DM}$ hastasında nokturnal hipoglisemi ataklarında QTC intervalinde kısalma gerçekleştiğini göstermişlerdir (30).

\section{Çalışmanın kısıtıııkları}

Çalışmanın temel kısıtııı̆ı hastaların uzun dönem takiplerinin olmamasıdır. Hastalarda aritmik riskin belirteçleri değerlendirilirken gerçek sonlanım olması gereken aritmik olay değerlendirilememiştir. Ancak önemli sonuçlardan birisi de hiperglisemik dönemde artan risktir ve hastaları aritmik olay artışını izlemek için hiperglisemik kalmasını kabul etmek etik olarak kabul edilemez bir durumdur. Bir diğer kısıtılık düşük hasta sayısı olarak belirtilebilse de mevcut çalışma DM hastalarında EKG bozuklukları açısından yapılan çalışmalar içinde hasta sayısı bakımından ortalamanın üstündedir. Aynı hastanın hiperglisemik ve normoglisemik dönemlerdeki verileri karşılaştırıldığı için çok etkisi olacağı düşünülmese de hastaların diyabet tanı süreleri homojen değildir ve hastalarda KON açısından sintigrafi gibi ek tanısal işlem yapılmamıştır.

\section{Sonuç}

Tip 2 DM hastalarında kan glikoz düzeyi yüksekliği sırasında QTc, Tpe, TpeQTc ve Tpec gibi miyokardiyal repolarizasyonu gösteren parametrelerde uzama mevcuttur ve bu durum hiperglisemik DM hastalarında aritmi riski arttıran bir durum olabilir. Ayrıca glisemik kontrol sonrası bozulmuş miyokardiyal repolarizasyonda kısmi düzelme olsa da QTc ve Tpec değerlerinin sağlıklı kontrollere göre yüksekliği devam etmektedir.

Çıkar çatışması: Yazar bu çalışma ile ilgili herhangi bir çıkar çatışması olmadığını beyan eder.

\section{Kaynaklar}

1. Morrish NJ, Wang SL, Stevens LK, Fuller JH, Keen H. Mortality and causes of death in the WHO Multinational Study of Vascular Disease in Diabetes. Diabetologia. 2001; 44 (Suppl 2): 14-21.

2. Forbes JM, Cooper ME. Mechanisms of diabetic complications. Physiol Rev. 2013; 93 (1): 137-88.

3. El-Menyar AA. Dysrhythmia and electrocardiographic changes in diabetes mellitus: pathophysiology and impact on the incidence of sudden cardiac death. J Cardiovasc Med (Hagerstown). 2006; 7 (8): 580-5.

4. Balkau B, Jouven X, Ducimetiere P, Eschwege E. Diabetes as a risk factor for sudden death. Lancet. 1999; 354 (9194): 1968-9.

5. Grisanti LA. Diabetes and Arrhythmias: Pathophysiology, Mechanisms and Therapeutic Outcomes. Frontiers in physiology. 2018; 9: 1669.

6. Panikkath R, Reinier K, Uy-Evanado A et al. Prolonged Tpeak-to-tend interval on the resting ECG is associated with increased risk of sudden cardiac death. Circ Arrhythm Electrophysiol. 2011; 4 (4): 441-7.

7. Aro AL, Reinier K, Rusinaru $\mathrm{C}$ et al. Electrical risk score beyond the left ventricular ejection fraction: prediction of sudden cardiac death in the Oregon Sudden Unexpected Death Study and the Atherosclerosis Risk in Communities Study. Eur Heart J. 2017; 38 (40): 3017-25. 
8. Morin DP, Saad MN, Shams OF et al. Relationships between the T-peak to T-end interval, ventricular tachyarrhythmia, and death in left ventricular systolic dysfunction. Europace. 2012; 14 (8): 1172-9.

9. Kittnar O. Electrocardiographic changes in diabetes mellitus. Physiol Res. 2015;64 Suppl 5: S559-66.

10. Zdarska D, Peliskova $P$, Charvat $\mathrm{J}$ et al. ECG body surface mapping (BSM) in type 1 diabetic patients. Physiol Res. 2007; 56 (4): 403-10.

11. Palova S, Szabo K, Charvat J, Slavicek J et al. ECG body surface mapping changes in type 1 diabetic patients with and without autonomic neuropathy. Physiol Res. 2010; 59 (2): 203-9.

12. Kuzu F. The effect of type 2 diabetes on electrocardiographic markers of significant cardiac events. Pakistan journal of medical sciences. 2018;34(3):626-32.

13. Krahulec B, Mikes Z, Balazovjech I. The effect of cardiovascular autonomic neuropathy on resting ECG in type 1 diabetic patients. Bratisl Lek Listy. 2002;103(2):54-8.

14. Antzelevitch C, Sicouri S, Di Diego JM et al. Does Tpeak-Tend provide an index of transmural dispersion of repolarization? Heart Rhythm. 2007; 4 (8): 1114-6; author reply 6-9.

15. Chua KC, Rusinaru C, Reinier K et al. Tpeak-to-Tend interval corrected for heart rate: A more precise measure of increased sudden death risk? Heart Rhythm. 2016; 13 (11):2181-5.

16. Creager MA, Luscher TF, Cosentino F, Beckman JA. Diabetes and vascular disease: pathophysiology, clinical consequences, and medical therapy: Part I. Circulation. 2003; 108 (12): 1527-32.

17. Dimitropoulos G, Tahrani AA, Stevens MJ. Cardiac autonomic neuropathy in patients with diabetes mellitus. World journal of diabetes. 2014; 5 (1): 17-39.

18. Stevens MJ, Raffel DM, Allman KC et al. Cardiac sympathetic dysinnervation in diabetes: implications for enhanced cardiovascular risk. Circulation. 1998; 98 (10): 961-8.

19. Adebayo RA, Ikwu AN, Balogun MO et al. Evaluation of the indications and arrhythmic patterns of 24 hour Holter electrocardiography among hypertensive and diabetic patients seen at OAUTHC, Ile-Ife Nigeria. Diabetes Metab Syndr Obes. 2014; 7: 565-70.

20. Breidthardt T, Christ M, Matti M et al. QRS and QTc interval prolongation in the prediction of long-term mortality of patients with acute destabilised heart failure. Heart. 2007; 93 (9): 1093-7.

21. Brooksby $P$, Batin PD, Nolan J et al. The relationship between QT intervals and mortality in ambulant patients with chronic heart failure. The United Kingdom Heart Failure Evaluation and Assessment of Risk Trial (UKHEART). European Heart Journal. 1999; 20 (18): 1335-41.

22. Seegers $\mathrm{J}$, Conen $\mathrm{D}$, Jung $\mathrm{K}$ et al. Sex difference in appropriate shocks but not mortality during long-term follow-up in patients with implantable cardioverter-defibrillators. Europace. 2016; 18 (8): 1194-202.

23. Gupta P, Patel C, Patel $\mathrm{H}$ et al. T(p-e)/QT ratio as an index of arrhythmogenesis. J Electrocardiol. 2008; 41 (6): 567-74.

24. Liu T, Brown BS, Wu Y, Antzelevitch C, Kowey PR, Yan GX. Blinded validation of the isolated arterially perfused rabbit ventricular wedge in preclinical assessment of drug-induced proarrhythmias. Heart Rhythm. 2006; 3 (8): 948-56.

25. Antzelevitch $\mathrm{C}$. Role of spatial dispersion of repolarization in inherited and acquired sudden cardiac death syndromes. Am J Physiol Heart Circ Physiol. 2007; 293 (4): H2024-38.

26. Shimizu M, Ino H, Okeie $K$ et al. T-peak to T-end interval may be a better predictor of high-risk patients with hypertrophic cardiomyopathy associated with a cardiac troponin I mutation than QT dispersion. Clin Cardiol. 2002; 25 (7): 335-9.

27. Marfella R, Nappo F, De Angelis L, Siniscalchi M, Rossi F, Giugliano D. The effect of acute hyperglycaemia on QTc duration in healthy man. Diabetologia. 2000; 43 (5): 571-5.

28. Tokatli A, Kiliçaslan F, Alis M, Yiginer O, Uzun M. Prolonged Tp-e Interval, Tp-e/QT Ratio and Tp-e/QTc Ratio in Patients with Type 2 Diabetes Mellitus. Endocrinology and metabolism (Seoul, Korea). 2016; 31 (1): 10512.

29. Ewing DJ, Neilson JM. QT interval length and diabetic autonomic neuropathy. Diabet Med. 1990; 7 (1): 23-6.

30. Koivikko ML, Kentta T, Salmela PI, Huikuri HV, Perkiomaki JS. Changes in cardiac repolarisation during spontaneous nocturnal hypoglycaemia in subjects with type 1 diabetes: a preliminary report. Acta Diabetol. 2017; 54 (3): 251-6. 